\title{
Elevated XRCC5 expression level can promote temozolomide resistance and predict poor prognosis in glioblastoma
}

\author{
I-NENG LEE ${ }^{1}$, JEN-TSUNG YANG ${ }^{2,3}$, CHENG HUANG $^{4,5}$, \\ HSIU-CHEN HUANG ${ }^{6}$, YU-PING WU ${ }^{1}$ and JUI-CHIEH CHEN ${ }^{7}$ \\ Departments of ${ }^{1}$ Medical Research and ${ }^{2}$ Neurosurgery, Chang Gung Memorial Hospital, \\ Chiayi 61363; ${ }^{3}$ College of Medicine, Chang Gung University, Tao-Yuan 33302; \\ ${ }^{4}$ Department of Biotechnology and Laboratory Science in Medicine, National Yang-Ming University, \\ Taipei 11221; ${ }^{5}$ Department of Earth and Life Sciences, University of Taipei, Taipei 11153; \\ ${ }^{6}$ Department of Applied Science, National Tsing Hua University South Campus, Hsinchu 30014; \\ ${ }^{7}$ Department of Biochemical Science and Technology, National Chiayi University, Chiayi 60004, Taiwan, R.O.C.
}

Received June 11, 2020; Accepted March 4, 2021

DOI: $10.3892 / \mathrm{ol} .2021 .12704$

\begin{abstract}
Drug resistance and disease recurrence are important contributors for the poor prognosis of glioblastoma multiforme (GBM). Temozolomide (TMZ), the standard chemotherapy for GBM treatment, can methylate DNA and cause the formation of double-strand breaks (DSBs). X-ray repair cross complementing 5 (XRCC5), also known as Ku80 or Ku86, is required for the repair of DSBs. The present study identified novel determinants that sensitize cells to TMZ, using an array-based short hairpin (sh)RNA library. Then, cBioportal, Oncomine, and R2 databases were used to analyze the association between gene expression levels and clinical characteristics. Subsequently, lentiviral shRNA or pCMV was used to knockdown or overexpress the gene of interest, and the effects on TMZ sensitivity were determined using a MTT assay and western blot analysis. TMZ-resistant cells were also established and were used in in vitro and in vivo experiments to analyze the role of the gene of interest in TMZ resistance. The results indicated that XRCC5 was effective in enhancing TMZ cytotoxicity. The results from the bioinformatics analysis revealed that XRCC5 mRNA expression levels were associated with clinical deterioration and lower overall survival rates. In addition, XRCC5 knockdown could significantly increase TMZ sensitivity in GBM cells, while XRCC5 overexpression caused the cancer cells to be resistant to TMZ. Both the in vivo and in vitro experiments showed that TMZ treatment could induce expression of XRCC5 in TMZ-resistant cells. Taken
\end{abstract}

Correspondence to: Professor Jui-Chieh Chen, Department of Biochemical Science and Technology, National Chiayi University, 300 Syuefu Road, Chiayi 60004, Taiwan, R.O.C.

E-mail: jcc@mail.ncyu.edu.tw

Key words: glioblastoma multiforme, temozolomide, X-ray repair cross-complementing protein, drug resistance together these findings suggested that XRCC5 could be a promising target for GBM treatment and could also be used as a diagnostic marker for refractory GBM.

\section{Introduction}

Glioblastoma multiforme (GBM), also known as astrocytoma grade IV (1), is one of the most common and fatal forms of malignant primary brain tumor. In total, $14.6 \%$ of all brain tumors in the United States between 2012 and 2016 were GBM, with a 5-year survival rate of $6.8 \%$ (2). Temozolomide (TMZ), an oral alkylating agent, is the first-line chemotherapy drug for GBM, as it can cross the blood-brain barrier (3). TMZ causes the methylation of the $\mathrm{O}^{6}$ position of guanine in DNA, leading to a mismatch between $\mathrm{O}^{6}$-methylguanine and thymine. Subsequently, the cells undergo DNA replication and the mismatch repair promotes the formation of DNA double-strand breaks (DSBs) (4), which may further trigger GBM cell death (5-7).

Most patients show a significant initial response to TMZ; however, the overall response to $\mathrm{TMZ}$ chemotherapy is still poor due to the development of drug resistance. TMZ resistance may involve multiple mechanisms, such as DNA methyltransferase (MGMT) and DNA repair (8-10), and accelerating the repair of DSBs can enhance the TMZ chemical resistance of GBM cells (11-13). The molecular mechanism mediating TMZ resistance has not been fully understood; therefore, an improved understanding of TMZ resistance will assist with the development of new sensitizers to improve the efficacy of TMZ treatment. The standard of care for patients with GBM is maximum tumor resection, followed by radiotherapy and adjuvant chemotherapy with TMZ; however, patients globally rarely survive for $>2$ years after diagnosis $(14,15)$. Therefore, new treatment strategies are required to improve patient survival.

RNA interference (RNAi) is a revolutionary technique for studying the biological functions of a particular gene, by silencing its gene expression $(16,17)$. A lentiviral short hairpin 
(sh)RNA subset was used in the present study to identify genes that increase TMZ sensitivity in GBM cells. Such screening methods have proven to be effective tools for identifying key targets of drug sensitivity $(18,19)$.

$\mathrm{X}$-ray repair cross-complementing protein 5 (XRCC5), also known as Ku80 or Ku86, is encoded by a gene located on human chromosome $2 q 33$. The non-homologous end joining (NHEJ) is the predominant DSB repair mechanism in human cells (20). During the repair process, DSB is first recognized by the heterodimer composed of XRCC6 (also denoted as Ku70)/XRCC5 in NHEJ, then DNA-dependent protein kinase catalytic subunit (DNA-PKcs) is subsequently recruited to repair the DSB $(21,22)$. Several studies have determined that the increased protein expression level of XRCC5 has been associated with treatment resistance and the development of numerous malignant tumors, and if there is reduced XRCC5 protein expression, cancer cells have reduced resistance to treatment and degree of malignancy (23-29). However, whether XRCC5 affects TMZ sensitivity in GBM is completely unknown.

Numerous large public databases provide complete genetic information and clinical data, that enables bioinformatics tools to analyze associations between gene expression levels and clinical pathological features. These advances can assist in quickly evaluating the differentially expressed genes associated with progression, diagnosis and prognosis in different cancer types, which is an important foundation for developing potential therapeutic strategies (30-32). Bioinformatics data analysis was also used to examine whether XRCC5 could be a clinical indicator for the progression and prognosis in GBM in the present study. Acquired drug resistance is a limiting factor in the clinical treatment of $\operatorname{GBM}(33,34)$. The present study aimed to investigate whether XRCC5 could be involved in TMZ resistance, which may indicate a potential therapeutic target to improve the efficacy of TMZ treatment.

\section{Materials and methods}

Cell culture. The human glioblastoma cell lines: U-87 MG (cat. no. HTB-14; glioblastoma of unknown origin), M059K (cat. no. CRL-2365) and DBTRG-05MG (cat. no. CRL-2020) were purchased from American Type Culture Collection (ATCC). All the cells were cultured in DMEM, supplemented with $10 \% \mathrm{FBS}$ and $100 \mathrm{U} / \mathrm{ml}$ penicillin/streptomycin (complete medium) at $37^{\circ} \mathrm{C}$ in a humidified incubator with $5 \% \mathrm{CO}_{2}$. The medium was refreshed every 2-3 days. After reaching $90 \%$ confluence, the cells were washed with PBS and trypsinized with $0.05 \%$ trypsin-EDTA. The trypsinization effect was neutralized with DMEM, supplemented with 10\% FBS. Subsequently, the cells were centrifuged at $350 \mathrm{x}$ g for $5 \mathrm{~min}$ at room temperature and the cell pellet was resuspended in the complete medium. The cell suspension was diluted 1:1 (v/v) with $0.4 \%$ trypan blue and the viable cells (unstained) were counted with a hemocytometer. DMEM, FBS, trypsin-EDTA and trypan blue solution were purchased from Thermo Fisher Scientific, Inc. All the experiments were performed within 1 year following purchasing the cells from ATCC.

Lentivirus array-based shRNA library screening. The vesicular stomatitis virus G protein (VSV-G)-pseudotyped lentivirus-based subset was obtained from the National RNAi Core Facility, Academia Sinica (Taipei, Taiwan). The kinase and phosphatase (KP) gene subset was selected for screening. The RNAi Consortium (TRC) designed multiple distinct shRNA clones to target specific genes. A total of 428 shRNAs targeting 84 kinases or phosphatases were used for the functional screen in a 96-well format (one shRNA per well). Each viral clone, with a unique target sequence, represented a kinase/phosphatase and each infected cell would produce a gene-specific knockdown effect. In brief, for a single shRNA clone, the U-87 MG cells were seeded $\left(3 \times 10^{3}\right.$ cells/well) in 96 -well plates, $24 \mathrm{~h}$ prior to infection. The cells were then infected with KP subset lentiviruses (multiplicity of infection, 3) in the presence of $8 \mu \mathrm{g} / \mathrm{ml}$ polybrene (Sigma-Aldrich; Merck $\mathrm{KGaA}$ ) at $37^{\circ} \mathrm{C}$ in a humidified incubator with $5 \% \mathrm{CO}_{2}$. The effect of each gene knockdown on TMZ sensitivity in the U-87MG cells was analyzed using an MTT assay as later described.

Cell cytotoxicity. After U-87MG cells were transduced with shRNA-expressing lentivirus for $48 \mathrm{~h}$, the DMEM with FBS was removed and replaced with fresh DMEM. Each shRNA clone infection was performed in duplicate, in two independent 96-well plates. Then, each replicate was treated with either vehicle (DMSO) or $500 \mu \mathrm{M} \mathrm{TMZ}$ for $48 \mathrm{~h}$ at $37^{\circ} \mathrm{C}$ in a humidified incubator with $5 \% \mathrm{CO}_{2}$. A MTT assay was used to evaluate relative cell viability. Briefly, the cells were plated at a density of $5 \times 10^{3}$ cells/per well in $100 \mu 1$ complete medium and in 96-well microplates. After overnight incubation, the medium was replaced by serum-free medium, containing TMZ concentration $(0-1,000 \mu \mathrm{M})$. After incubation for $48 \mathrm{~h}$, the MTT reagent $(0.5 \mathrm{mg} / \mathrm{ml})$ was added to each well, then the cells were incubated for a further $4 \mathrm{~h}$. After incubation, the medium was removed and the purple formazan was solubilized with dimethyl sulfoxide (DMSO). The absorbance was measured at $570 \mathrm{~nm}$, with background subtraction at $630 \mathrm{~nm}$ using a Microplate ELISA Reader. The percentage of cell viability is shown relative to untreated cells. The MTT, TMZ and DMSO reagents were purchased from Sigma-Aldrich (Merck KGaA).

Public database analysis. XRCC5 mRNA expression level in human lower-grade glioma and GBM tissues were analyzed through cBioPortal (https://www.cbioportal.org/). Two datasets in cBioPortal were used: The Cancer Genome Atlas (TCGA) Pancancer Atlas dataset (https://www.cell.com/pb-assets/ consortium/pancanceratlas/pancani3/index.html) (including lower grade glioma [oligoastrocytoma $25.3 \%$, anaplastic astrocytoma $24.5 \%$, oligodendroglioma $22.6 \%$, anaplastic oligoastrocytoma $14.7 \%$, astrocytoma $12.6 \%$ and diffuse glioma $0.2 \%$ ) provisional dataset (http://gdac.broadinstitute. org/runs/stddata__2016_01_28/data/LGG/20160128/) (including lower grade glioma [astrocytoma $37.7 \%$, oligodendroglioma $36.8 \%$, oligoastrocytoma $25.3 \%$, encapsulated glioma $0.2 \%$, and low-grade glioma (nos) $0.2 \%]$ ). XRCC5 mRNA expression level in human br ain cancer tissues and normal brain tissues were analyzed through Oncomine (https://www.oncomine.org/). and the R2 Genomics Analysis and Visualization Platform (https://hgserver1.amc.nl/cgi-bin/r2/main.cgi). Median and interquartile ranges are presented. In addition, 
the online software R2 Genomics Analysis and Visualization Platform was used to analyze the correlation between XRCC5 expression and clinical prognosis. Kaplan-Meier curves were generated using the following datasets: Tumor Brain-Madhavan-550-MAS5.0-u133p2; 208642_s_at. (35), where a cut-off between high expression and low expression groups.

Lentiviral systems for XRCC5 knockdown. The pLKO.1-puro-based lentiviral vectors (harboring a specific shRNA encoding sequence, packaging plasmid pCMV-R8.91, and pMD) were obtained from the National RNAi Core Facility at Academia Sinica (Taipei, Taiwan). Recombinant lentiviruses were packaged according to the manufacturer's instructions. Lentivirus was produced by transfecting the $293 \mathrm{~T}$ cells with the lentiviral vector $(4 \mu \mathrm{g})$ plus the packaging plasmids, pCMV $\Delta$ R8.91 $(4 \mu \mathrm{g})$ and pMD $(0.4 \mu \mathrm{g})$ using TurboFect reagent (Thermo Fisher Scientific, Inc.). The lentiviral plasmids targeting XRCC5 were TRCN0000288701 (shXRCC5\#1: 5'CCGGCGTGGGCTTTACCATGAGTAACTCGAGTTACT CATGGTAAAGCCCACGTTTTTG3'), TRCN0000295856 (shXRCC5\#2: 5'CCGGAGAGGAAGCCTCTGGAAGTTCCT CGAGGAACTTCCAGAGGCTTCCTCTTTTTTG3') and TRC2-pLKO_TRC005 (scrambled shControl). U-87MG cells were exposed to lentiviral supernatants containing $8 \mu \mathrm{g} / \mathrm{ml}$ polybrene for $24 \mathrm{~h}$, the medium was replaced and then they were incubated for another $48 \mathrm{~h}$. Puromycin $(5 \mu \mathrm{g} / \mathrm{ml})$ was added $48 \mathrm{~h}$ after transfection to select stable cell lines. Stable cells were collected to determine knockdown efficiency using western blot analysis, and the effect on TMZ sensitivity was evaluated using an MTT assay and western blot analysis.

Western blot analysis. The GBM cells were lysed with RIPA buffer (25 mM Tris- $\mathrm{HCl} \mathrm{pH} 7.6,150 \mathrm{mM} \mathrm{NaCl}, 1 \% \mathrm{NP}-40$, $1 \%$ sodium deoxycholate and $0.1 \%$ SDS) containing a protease inhibitor cocktail. The protein concentration was determined using a Pierce BCA Protein Assay kit (cat. no. 23235; Pierce; Thermo Fisher Scientific, Inc.) using bovine serum albumin (BSA; cat. no. 23209; Pierce; Thermo Fisher Scientific, Inc.) as a standard. An equal amount of total protein (40 $\mu \mathrm{g} /$ lane) was resolved using an 8-15\% SDS-PAGE and transferred to PVDF membranes (EMD Millipore). The membrane was blocked with 5\% BSA (Thermo Fisher Scientific, Inc.), then probed with the following primary antibodies at $4^{\circ} \mathrm{C}$ overnight: XRCC5 (1:5,000; cat. no. 16389-1-AP; ProteinTech Group, Inc.), cleaved caspase-3 (1:1,000; cat. no. 9661; Cell Signaling Technology, Inc.), cleaved PARP (1:1,000; cat. no. ab32064; Abcam) $\alpha$-tubulin $(1: 10,000$; cat. no. 05-829; EMD Millipore). After washing with Tris-buffered saline and $0.05 \%$ Tween-20, the membrane was subsequently incubated with appropriate horseradish peroxidase-coupled secondary antibodies: Goat Anti-Rabbit IgG (1:5,000; cat. no. 20202; Biotium, Inc.) and goat anti-Mouse IgG (1:5,000; cat. no. 115-035-003; Jackson ImmunoResearch Labs, Inc.) for $1 \mathrm{~h}$ at room temperature. Bound antibodies were detected using enhanced chemiluminescence reagents (Merck KGaA) and signals were visualized using X-ray film. Signal intensities were quantified using the UN-SCAN-IT gel 6.1 software (Silk Scientific, Inc.).
XRCC5 overexpression. According to the manufacturer's instructions, the U-87MG and M059K cells were transfected with XRCC5 overexpression plasmid ( $1 \mu \mathrm{g}$; pCMV3-XRCC5) or empty vector ( $1 \mu \mathrm{g}$; pCMV3) using TurboFect transfection reagent (Thermo Fisher Scientific, Inc.) at $37^{\circ} \mathrm{C}$ in a humidified incubator with $5 \% \mathrm{CO}_{2}$. All plasmids were purchased from Sino Biological Inc. After 48 h of transfection, cells were collected to determine the overexpression efficiency using quantitative (q)PCR or western blot analysis, and the effect on TMZ sensitivity was evaluated using an MTT assay.

Reverse transcription-qPCR. Total RNA was isolated using TRIzol $^{\circledR}$ (Invitrogen; Thermo Fisher Scientific, Inc.). RT was conducted using the PrimeScript RT reagent kit (Takara Bio Inc.) using the following conditions: Incubation at $37^{\circ} \mathrm{C}$ for $30 \mathrm{~min}$ and heating to $85^{\circ} \mathrm{C}$ for $5 \mathrm{sec}$. qPCR was performed using the KAPA SYBR ${ }^{\circledR}$ FAST qPCR Master Mix (2X) kit (Roche Diagnostics) and the StepOnePlus sequence detection system (Applied Biosystems; Thermo Fisher Scientific, Inc.) with the following thermal cycling conditions: Initial denaturation at $95^{\circ} \mathrm{C}$ for $30 \mathrm{sec}$, denaturation at $95^{\circ} \mathrm{C}$ for $2 \mathrm{~min}$ and annealing/extension at $60^{\circ} \mathrm{C}$ for $30 \mathrm{sec}$ for 40 cycles. The following primers were used: XRCC5 forward, 5'-GACGTG GGCTTTACCATGAGT-3' and reverse, 5'-TCAGTGCCATCT GTACCAAAC-3; and GAPDH forward 5'-ACATCCCCTCAC CAATAACAAC-3' and reverse, 5'-TAGCCAAATCATACT GCTCGTC-3'. All experiments were performed according to the manufacturer's instructions. Relative gene expression was calculated using the comparative $\mathrm{Cq}\left(2^{-\Delta \Delta \mathrm{Cq}}\right)$ method (36) and normalized to GAPDH.

Establishment of TMZ-resistant cells. The TMZ-resistant cell lines, DBTRG-05MG-R and U-87 MG-R were established using a step-wise exposure of the parental cells (DBTRG-05MG and U-87 MG cell lines, respectively) to increasing concentrations of TMZ, ranging from 15.625 to $250 \mu \mathrm{M}$ for $>6$ months. TMZ-resistant and parent cells were collected to analyze TMZ sensitivity using an MTT assay and western blot analysis, and the levels of XRCC5 protein under TMZ treatment were also assessed using western blot analysis.

Xenograft mouse model. A total of six female BALB/c nude mice (4-6 weeks old, 15-20 g weight) were purchased from BioLASCO Co., Ltd. and maintained in appropriate sterile filter capped cages at an animal center certified by the Association for Assessment and Accreditation of Laboratory Animal Care International at Chang Gung Memorial Hospital (Chiayi, Taiwan). Mice were kept in an environment with a temperature of $23-25^{\circ} \mathrm{C}$, a relative humidity of $50-70 \%$ and a light-dark cycle of $12 / 12 \mathrm{~h}$, with free access to food and water. The experiment was conducted in 2019. The U87MG and U87MG-R $\left(5 \times 10^{6}\right)$ cell lines were injected subcutaneously into the right flanks of the mice ( $n=3 /$ group). When the tumor volumes (length $\mathrm{x}$ width ${ }^{2} \mathrm{x} 0.5$ ) had reached $\sim 60 \mathrm{~mm}^{3}$, as measured by digital calipers, the mice were administered with TMZ (10 mg/kg), once every 3 days for 15 days by intraperitoneal injection. The experiment was terminated on the 15 th day and mice were euthanized with excess $\mathrm{CO}_{2}$, with a 10-30\% volume displacement rate 

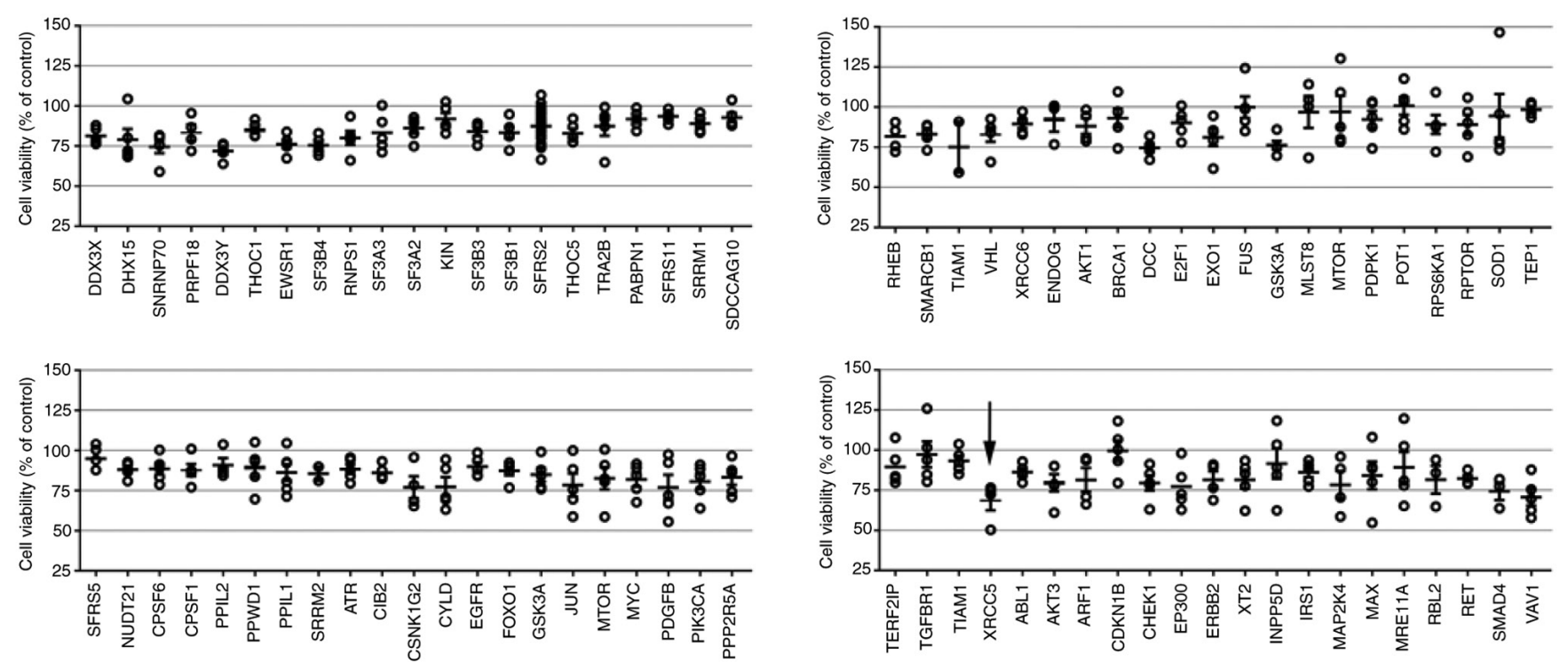

Figure 1. Array-based shRNA library was used to screen genes that can increase TMZ drug sensitivity. In total, 84 genes (equivalent to 428 shRNA clones) were screened to identify the effect of knockdown on TMZ cytotoxicity. For each shRNA clone, relative cell viability was calculated as the percentage of untreated cells. TMZ, temozolomide; sh, short hairpin.

per minute. The death of the mice was assessed by cardiac arrest and fixed/dilated pupils. All the mice were handled following the Animal Care and Use Guidelines of the Chang Gung Memorial Hospital (Chiayi, Taiwan) under a protocol approved by the Institutional Animal Care and Use Committee.

Immunohistochemistry. The specimens from the mice were fixed with $3.7 \%$ formaldehyde for $24 \mathrm{~h}$ at room temperature, then dehydrated in a series of graded alcohol baths and embedded in paraffin. The samples were cut into sections $(4-\mu \mathrm{m})$ and heated at $65^{\circ} \mathrm{C}$ for $30 \mathrm{~min}$. The sections were then de-paraffinized with xylene and rehydrated with a descending alcohol series (100, 70, 50 and 30\%) followed by distilled water. Next, tissues treated with $5 \%$ hydrogen peroxide at room temperature for $20 \mathrm{~min}$, to inhibit endogenous peroxidase activity, then incubated with $1 \%$ BSA (Thermo Fisher Scientific, Inc.) for $1 \mathrm{~h}$ at room temperature to block non-specific binding. The slides were incubated overnight at $4^{\circ} \mathrm{C}$ with a primary antibody against XRCC5 (1:500; 16389-1-AP; ProteinTech Group, Inc.). At room temperature, the slides were incubated with goat anti-rabbit $\operatorname{IgG}(1: 10,000$; cat. no. AP132R; Sigma-Aldrich) The DAB-substrate chromogen solution (1:50) was subsequently added for $3 \mathrm{~min}$ at room temperature and the slides were counterstained with hematoxylin for $30 \mathrm{sec}$.

Statistical analysis. The data are presented as the mean \pm SEM, from at least 3 independent experiments. The box plots obtained by cBioPortal analysis data were presented as median and interquartile ranges. Statistical analysis for assessing significant differences between two groups was performed using a paired Student's t-test. For comparison among multiple groups, the data was analyzed using one-way ANOVA followed by Tukey's post hoc test. An unpaired Student's t-test was used for comparison of data between two groups from Oncomine. Survival analyses were performed using the R2 database algorithm and statistical significance levels for multiple testing were adjusted using Bonferroni's correction. $\mathrm{P}<0.05$ was considered to indicate a statistically significant difference.

\section{Results}

Array-based RNAi library for screening a novel gene to enhance TMZ sensitivity. To identify genes that could enhance TMZ cytotoxicity, a partial KP lentiviral shRNA library was screened in the U-87 MG cell line. Preliminary screening showed that XRCC5 was the most effective among the 84 genes and could increase TMZ cytotoxicity. In cells with XRCC5 knockdown and treated with TMZ, the average cell survival rate was $68.6 \pm 6.1 \%$. Knockdown of the VAV1 gene was the second most effective in increasing cell cytotoxicity with the average cell survival rate of $70.7 \pm 5.3 \%$ (Fig. 1).

XRCC5 expression is upregulated in GBM tissues and is associated with poor prognosis. To investigate the expression level of XRCC5 in clinical tissues, analysis tools of three publicly available databases were used. As shown in Fig. 2A, the cBioPortal online analysis tool to analyze two datasets in TCGA, the data showed that the expression level of XRCC5 mRNA in GBM was higher than that in low-grade gliomas. (TCGA, Pancancer Atlas dataset: Lower grade glioma, $\mathrm{n}=514$; GBM, $\mathrm{n}=592$; TCGA, Provisional dataset: Lower grade glioma, n=530; GBM, n=604). From the Pancancer Atlas data, $37.7 \%$ of the patients with lower grade glioma had astrocytoma, $36.8 \%$ had oligodendroglioma, $25.3 \%$ had oligoastrocytoma and $0.2 \%$ had encapsulated glioma. From the Provisional TCGA data, $25.3 \%$ of the patients with lower grade glioma had oligoastrocytoma, $24.5 \%$ had anaplastic astrocytoma, $22.6 \%$ oligodendroglioma, $14.7 \%$ had anaplastic oligoastrocytoma, $12.6 \%$ had astrocytoma and $0.2 \%$ had diffuse glioma. 

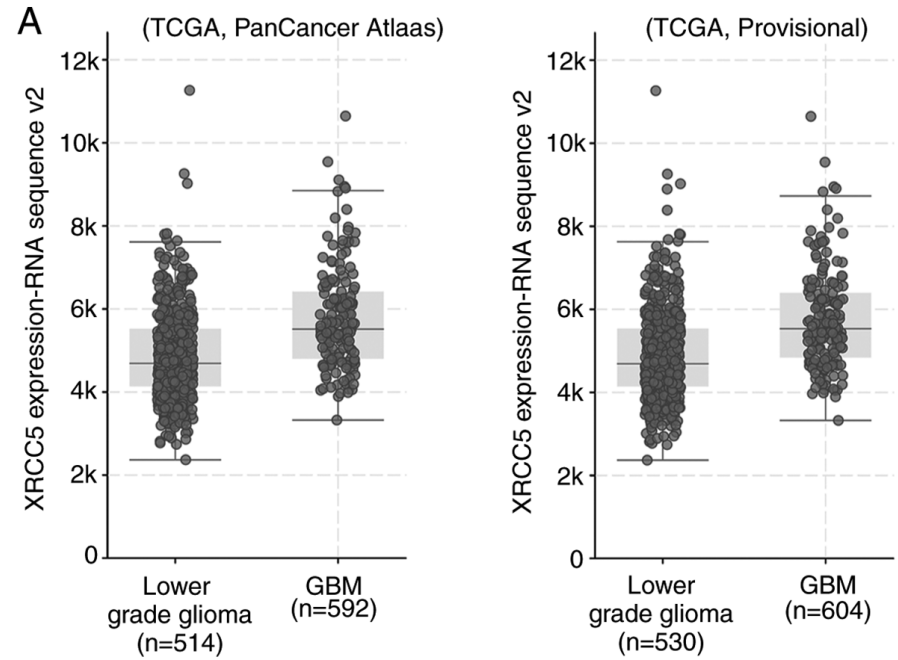

B
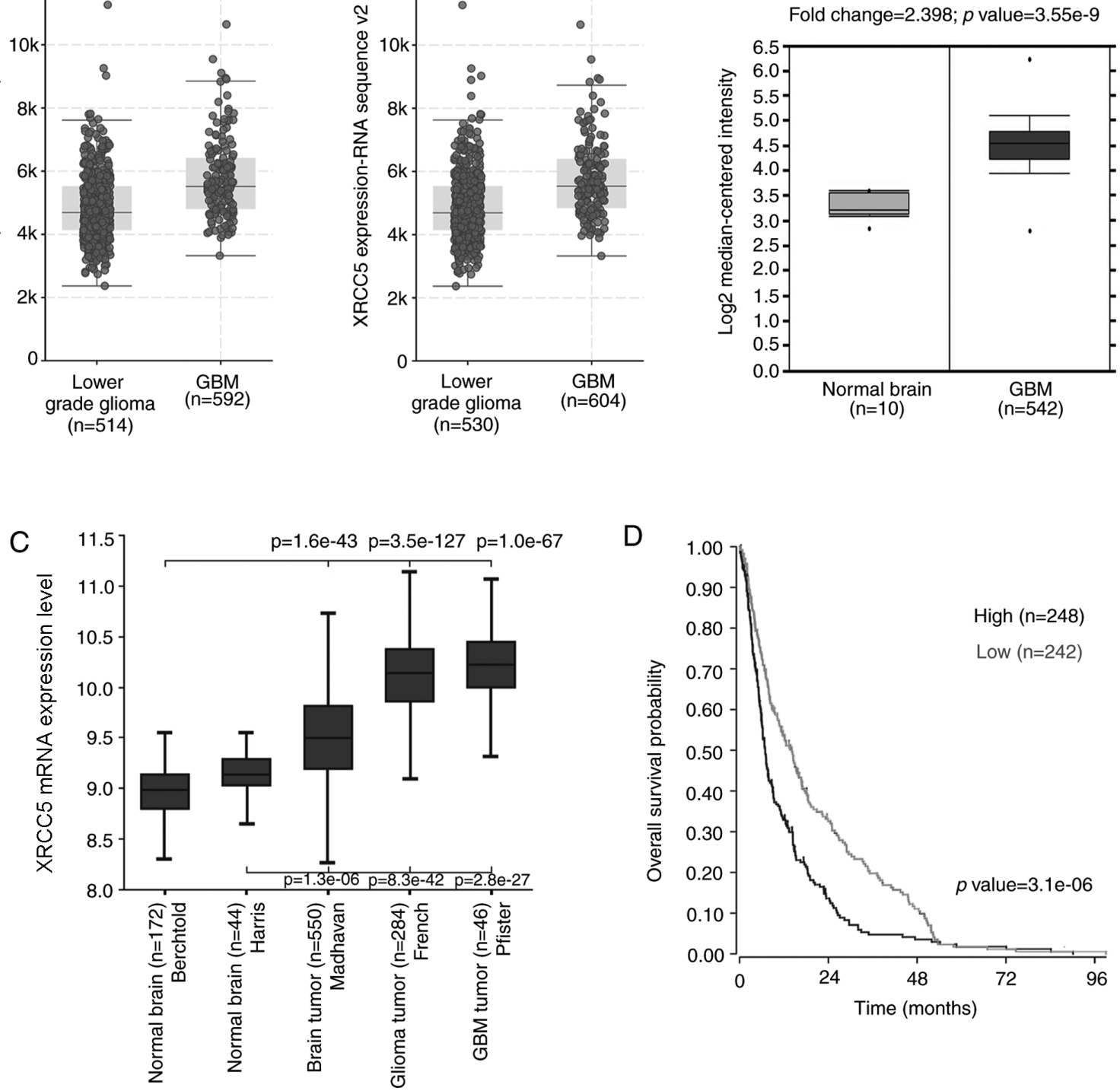

Figure 2. Clinical significance of XRCC5 in GBM. (A) Box plot showing mRNA expression levels of XRCC5 in GBM tissues and lower grade glioma tissues from cBioPortal database. (B) Box plots comparing XRCC5 mRNA expression levels in GBM and normal healthy brain tissue in data downloaded from Oncomine. (C) XRCC5 mRNA expression level in GBM and normal brain tissues were downloaded from the R2 Genomics Analysis and Visualization Platform database. (D) Clinical association of XRCC5 mRNA expression level and GBM patient survival was determined using Kaplan-Meier analysis from the R2 Genomics Analysis and Visualization Platform database. GBM, glioblastoma multiforme; TCGA, The Cancer Genome Atlas.

According to the Oncomine database, XRCC5 mRNA expression was significantly increased (fold-change, 2.398 ) in 542 GBM tissues compared with that in 10 normal brain tissues ( $\mathrm{P}=3.55 \times 10^{-9}$; Fig. 2B). In addition, data was also downloaded from the R2 Genomics Analysis and Visualization Platform database to compare the expression levels of XRCC5 mRNA in normal brain and tumor brain tissues. As shown in Fig. 2C, comparing brain cancer tissues, from three different datasets (Madhavan, French and Pfister) with normal brain tissues from two different datasets (Madhavan compared with Berchtold $\left(\mathrm{P}=1.6 \times 10^{-43}\right)$, French compared with Berchtold $\left(\mathrm{P}=3.5 \times 10^{-127}\right)$, Pfister compared with Berchtold $\left(\mathrm{P}=1.0 \times 10^{-67}\right)$; Madhavan compared with Haris $\left(\mathrm{P}=1.3 \times 10^{-6}\right)$, French compared with Haris $\left(\mathrm{P}=8.3 \times 10^{-42}\right)$, Pfister compared with Haris $\left(\mathrm{P}=2.8 \times 10^{-27}\right)$ it was found that XRCC5 was significantly higher in cancerous tissues compared with that in normal tissues. To investigate the association between XRCC5 expression level and clinical prognosis, the R2 database online tool was used and information was extracted from a tumor brain dataset (Madhavan-550 MAS5.0 u133p2) to analyze the potential effect of XRCC5 expression on the overall survival time of patients with GBM. The Kaplan-Meier curve in Fig. 2D showed that patients whose tumors had high expression levels of XRCC5 had poorer survival outcome $\left(\mathrm{P}=3.1 \times 10^{-6}\right)$.

XRCC5 is involved in TMZ-induced apoptosis in U-87MG cells. Next, the U-87MG cells were stably transfected with the lentiviral XRCC5 shRNA vector to determine whether XRCC5 expression level was associated with sensitivity to TMZ. Knockdown efficiency of XRCC5 was determined using western blot analysis (Fig. 3A). As Fig. 3B shows, knockdown of XRCC5 mRNA expression led to increased sensitivity to TMZ 


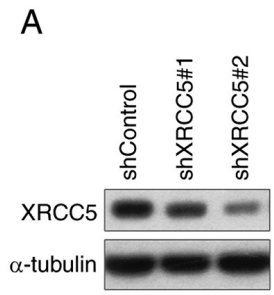

C
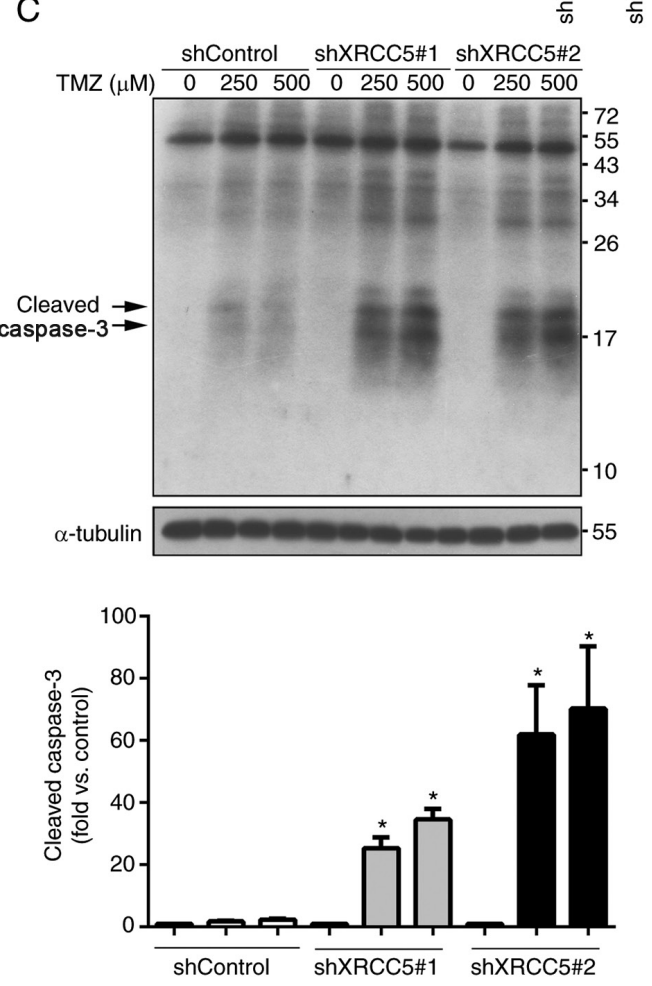

B
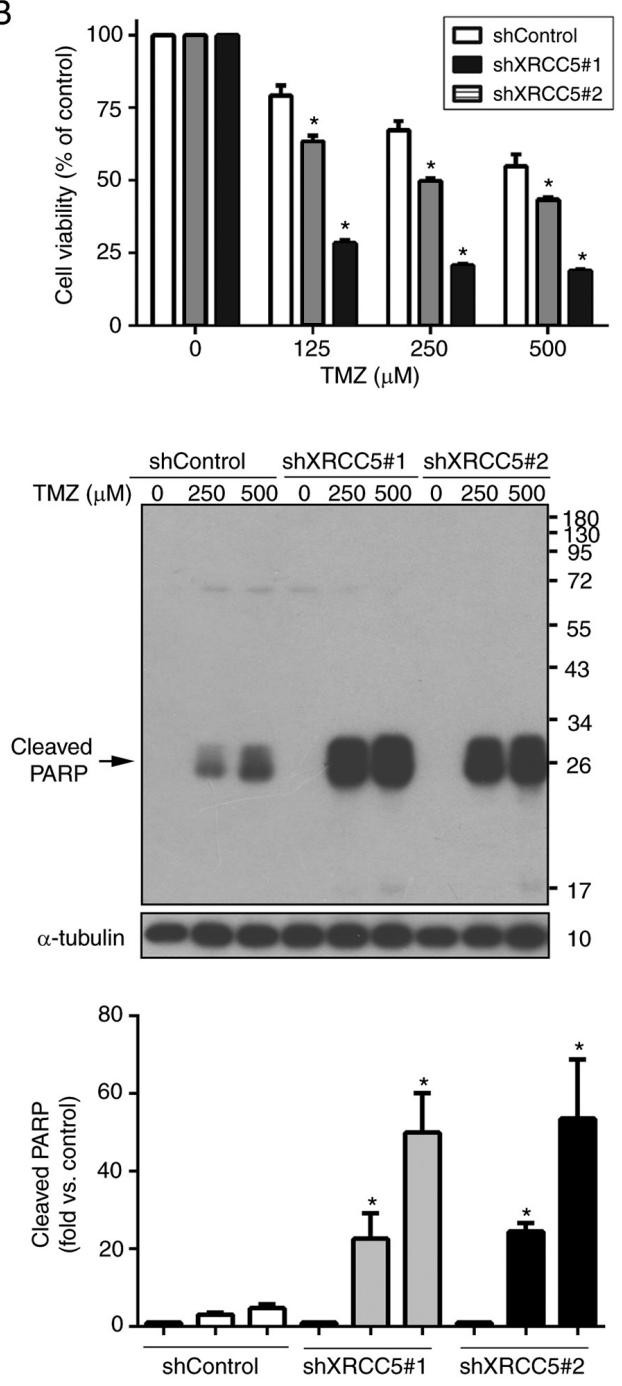

E
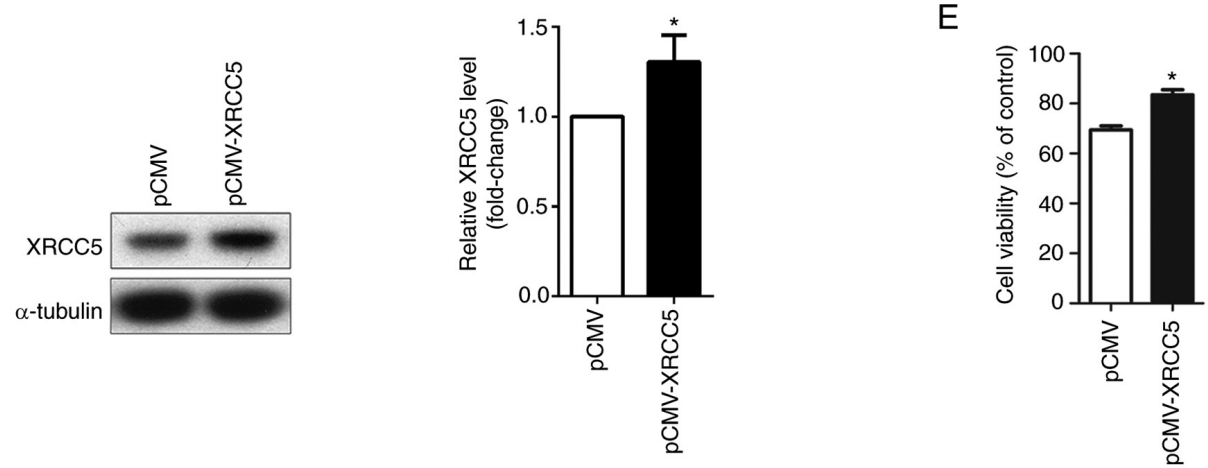

Figure 3. TMZ-mediated cytotoxicity is affected by XRCC5 expression levels in the U-87MG cells. (A) Protein expression levels of XRCC5 in shControl, shXRCC5\#1, and shXRCC5\#2 groups were examined using western blot analysis (left panel) and data was quantified using densitometry (right panel). ${ }^{*} \mathrm{P}<0.05$ compared with shControl. (B) The U-87MG cells were treated with increasing concentrations of TMZ $(0-500 \mu \mathrm{M})$ for $48 \mathrm{~h}$ and subsequently evaluated using a MTT assay. The data are presented from at least three independent experiments, performed in triplicate and expressed as mean the \pm SEM. ${ }^{*} \mathrm{P}<0.05$ compared with shControl. (C) Western blot analysis (top panel) was used to analyze the effect of XRCC5 knockdown on TMZ-induced expression levels of cleaved caspase-3 and cleaved PARP (as shown by the arrows) in the U-87MG cells and the data was quantitatively analyzed (bottom panel). $\alpha$-Tubulin was used as loading control. "P<0.05 compared with shControl. (D) the U-87MG cells were transiently transfected with XRCC5 overexpression vector and the protein expression levels were analyzed using western blot analysis (left panel) and subsequently quantified (right panel). ${ }^{*} \mathrm{P}<0.05$ compared with pCMV group. (E) Effect of XRCC5 overexpression on TMZ-induced cytotoxicity was determined using a MTT assay. The data are presented as the mean \pm SEM from 3 independent experiments. " $\mathrm{P}<0.05$ compared with pCMV group. TMZ, temozolomide; sh, short hairpin.

in a dose-dependent manner. To further clarify that XRCC5 was associated with TMZ-induced apoptosis, the cleaved forms of caspase-3 and PARP were also analyzed using western blot analysis. Knockdown of XRCC5, as shown in Fig. 3C, markedly increased the expression level of cleaved-caspase-3 and -PARP. In addition, XRCC5 overexpression was performed 

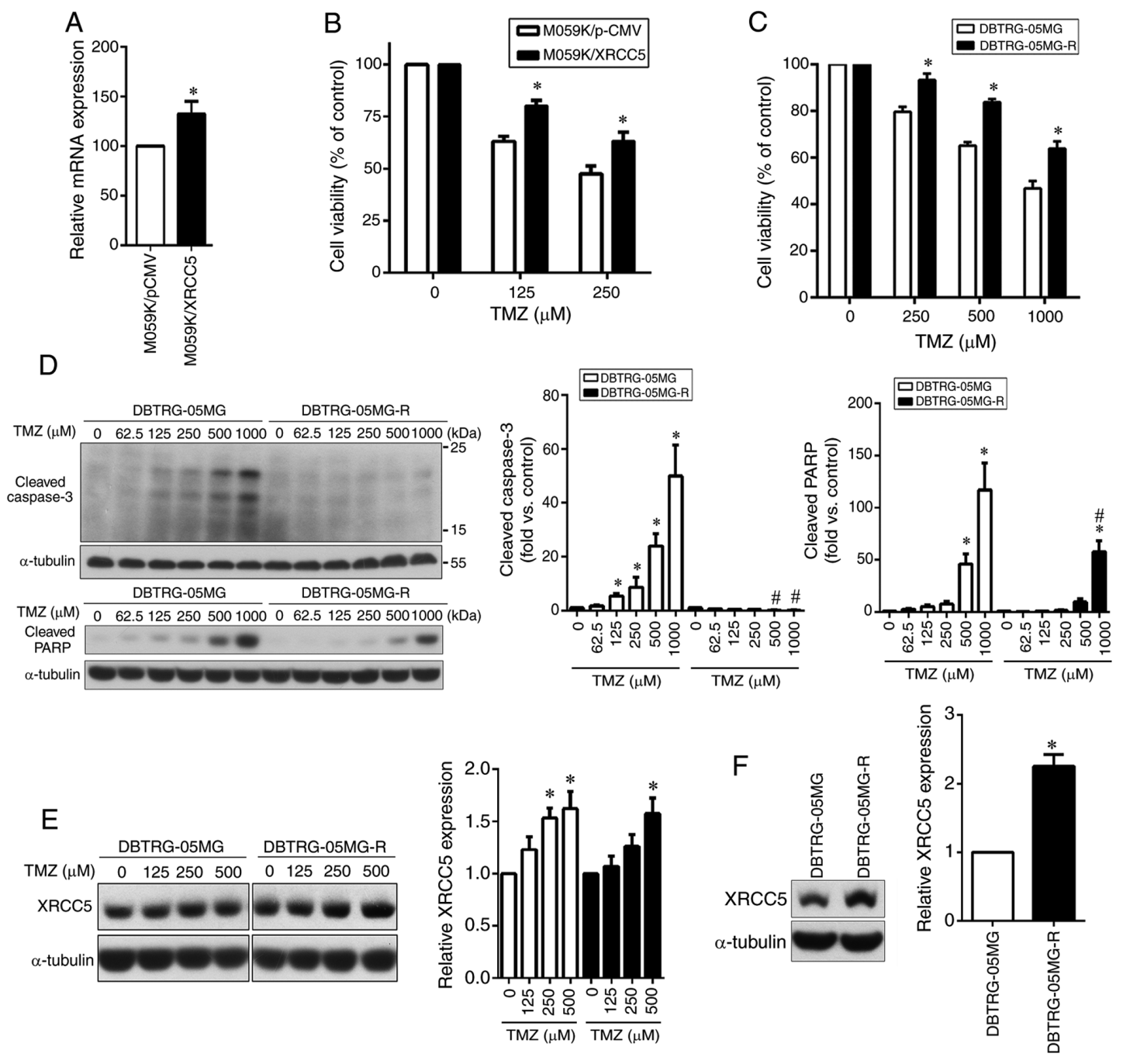

Figure 4. XRCC5 regulates TMZ sensitivity exists in other types of GBM cells. (A) mRNA expression level of XRCC5 in the M059K cell line transfected with pCMV-XRCC5 overexpression vector or pCMV was determined using reverse transcription-quantitative PCR. "P<0.05 compared with pCMV group. (B) The M059K cells transfected with pCMV-XRCC5 overexpression vector or pCMV were treated with increasing doses of TMZ (0-250 $\mu \mathrm{M})$ for $48 \mathrm{~h}$ and subsequently evaluated using a MTT assay. "P<0.05 compared with pCMV group. (C) The DBTRG-05MG and DBTRG-05MG-R cells were treated with increasing concentrations of TMZ $(0-1,000 \mu \mathrm{M})$ for $48 \mathrm{~h}$ and cell viability was determined using a MTT assay. "P<0.05 compared with DBTRG-05MG cells. (D) Dose-dependent effects of TMZ on the protein expression levels of cleaved caspase-3 and cleaved PARP in DBTRG-05MG and DBTRG-05MG-R cells were analyzed using western blot analysis (right panel) and quantified using densitometry (left panel). ${ }^{*} \mathrm{P}<0.05$ compared with untreated control. ${ }^{~} \mathrm{P}<0.05$ compared with DBTRG-05MG cells. (E) Dose-dependent effects of TMZ on the protein expression level of XRCC5 in the DBTRG-05MG and DBTRG-05MG-R cells were analyzed using western blot analysis (left panel) and quantified using densitometry (right panel). $\alpha$-Tubulin was used as loading control. ${ }^{*} \mathrm{P}<0.05$ compared with untreated control. (F) Western blot analysis was to determine the XRCC5 protein expression level in DBTRG-05MG and DBTRG-05MG-R cells (left panel) and the data was subsequently quantified using densitometry (right panel). ${ }^{*} \mathrm{P}<0.05$ compared with DBTRG-05MG cells. TMZ, temozolomide.

in the U-87MG cells to further verify the role of XRCC5 in TMZ sensitivity. XRCC5 overexpression was confirmed using western blot analysis (Fig. 3D) and overexpression of XRCC5 in the U-87MG cells significantly increased resistance to TMZ, as determined using a MTT assay (Fig. 3E).

High expression level of XRCC5 in GBM cells can promote $T M Z$ resistance. Subsequently, the pCMV-XRCC5 plasmid was transfected into the TMZ-sensitive M059K cell line to overexpress XRCC5 to analyze whether it could increase TMZ drug resistance. The XRCC5 overexpression level was confirmed using qPCR (Fig. 4A). The results revealed that overexpression of XRCC5 conferred increased resistance to TMZ compared with that in the M059K/pCMV group, as determined using a MTT assay (Fig. 4B). To further confirm the effect of XRCC5 against TMZ cytotoxicity in the GBM cell line, the TMZ-resistant DBTRG-05MG cell line was established. As determined by a MTT assay, the DBTRG-05MG-R cells were more resistant to TMZ compared with that in their parental cells (Fig. 4C). The protein expression levels of cleaved caspase-3 and cleaved PARP were also detected using western blot analysis, showing that the two cleaved markers of apoptosis were significantly increased in the TMZ-treated DBTRG-05MG cells compared with that in the DBTRG-05MG-R cells (Fig. 4D). Next, the dose-dependent effect of TMZ on XRCC5 protein expression in the DBTRG-05MG and DBTRG-05MG-R cells was investigated. As shown in Fig. 4E, the expression level of XRCC5 was increased in both cell lines in a dose-dependent manner. However, the basal expression level of XRCC5 in 
A

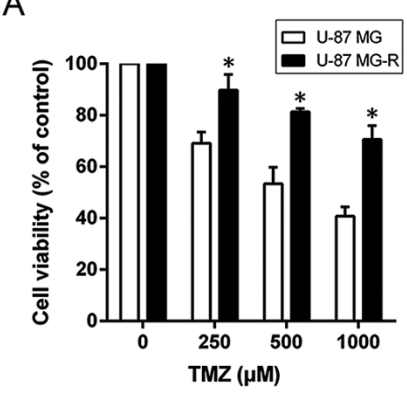

C
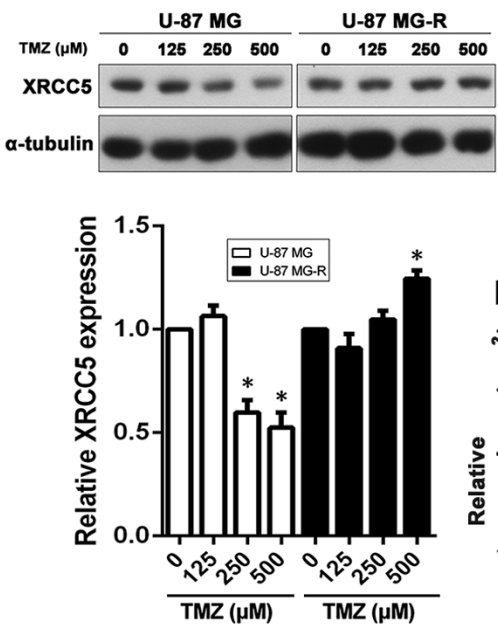

B
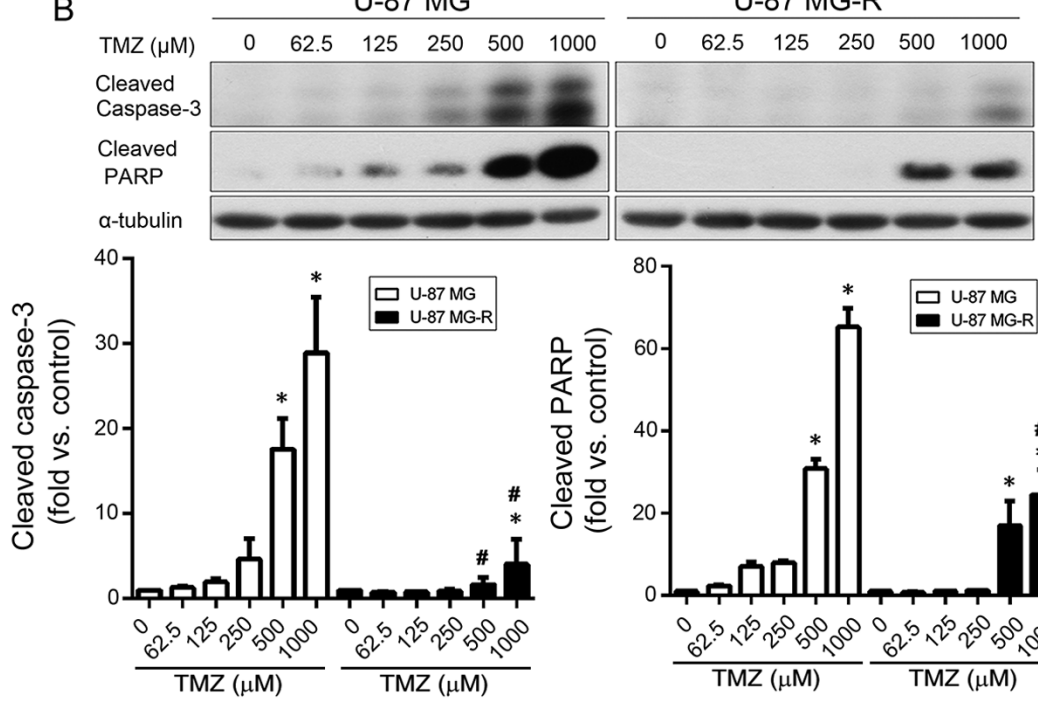

$\mathrm{E}$

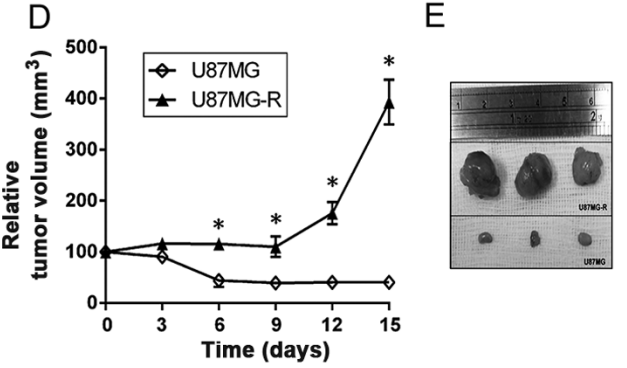

$\mathrm{F}$

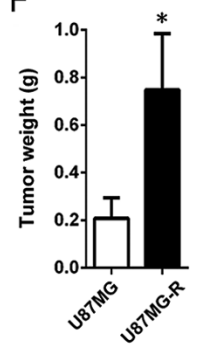

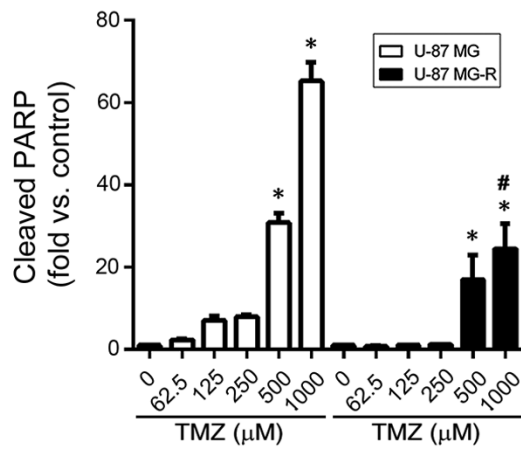

G

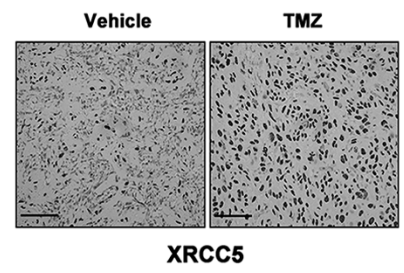

Figure 5. In vitro and in vivo experiments show that U-87MG-R cells maintain a high XRCC5 expression level and confer resistance to TMZ. (A) U-87MG and U-87MG-R cells were treated with increasing concentrations of TMZ $(0-1,000 \mu \mathrm{M})$ for $48 \mathrm{~h}$ and cell viability was determines using a MTT assay. $\mathrm{P}<0.05$ compared with U-87MG cells. (B) Dose-dependent effects of TMZ on the protein expression levels of cleaved caspase-3 and cleaved PARP in the U-87MG and U-87MG-R cells were analyzed using western blot (top panel) and the data was quantified using densitometry (bottom panel). ${ }^{*}<0.05$ compared with untreated control. ${ }^{\#} \mathrm{P}<0.05$ compared with U-87MG cells. (C) Dose-dependent effects of TMZ on the protein expression level of XRCC5 in the U-87MG and U-87MG-R cells was analyzed using western blot analysis (top panel) and the data was quantified using densitometry (bottom panel). ${ }^{*}<0.05$ compared with untreated group. (D) The U-87MG and U-87MG-R cells were injected subcutaneously into the flanks of nude mice. When the tumors had reached an appropriate size, the mice were treated with TMZ by intraperitoneal injection once every 3 days for 15 days ( $\mathrm{n}=3$ ). The tumor volume was measured using digital calipers. The relative tumor volumes were calculated every 3 days after treatment and compared to the tumor volume before start of the treatment (at day 0). ${ }^{*} \mathrm{P}<0.05$ vs. U-87MG group. Representative (E) tumor images and (F) tumor weight determined at the end of the experiment. Average tumor weight is presented as the mean \pm SEM. ${ }^{*} \mathrm{P}<0.05$ compared with U87MG group. (G) XRCC5 protein expression in the xenograft tumors in vehicle- and TMZ-treated groups were analyzed using immunohistochemical staining. Scale bar, $100 \mu \mathrm{m}$.

the TMZ-resistant cell line (DBTRG-05MG-R) was higher compared with that in the parental cell line (DBTRG-05MG) (Fig. 4F).

TMZ induces XRCC5 expression level in TMZ-resistant $U-87$ MG cells to promote resistance to TMZ both in vivo and in vitro. In addition to the DBTRG-05MG-R cell line, a TMZ-resistant U-87 MG cell line was also established (U-87 MG-R). As shown in Fig. 5A, the U-87 MG-R cells were highly resistant to TMZ compared with that in the parental cells. Following TMZ treatment, the protein expression levels of cleaved caspase- 3 and cleaved PARP were significantly higher in the U-87 MG cells compared with that in the U-87 MG-R cells, at high doses of TMZ (Fig. 5B). Next, the dose-dependent effects of TMZ on XRCC5 protein expression level in the parental and TMZ-resistant U-87 MG cell lines and the results showed that XRCC5 expression level, in the TMZ-resistant cells, continued to be expressed under 250 and $500 \mu \mathrm{M}$ TMZ treatments, while the parental cell line exhibited a significant decrease (Fig. 5C).
A nude mouse xenograft model was also used to further validate the effects of TMZ on XRCC5 expression level. As shown in Fig. 5D, TMZ effectively inhibited the tumor growth of the U-87 MG cells, but not the U-87 MG-R cells. The size of the subcutaneous tumor was also compared at the end of the experiment, as shown in Fig. 5E and it was found that the mean tumor weight of tumors derived from the U-87 MG-R cells was significantly higher compared with that in those derived from the U-87 MG cell tumors (Fig. 5F). Subsequently, the tumor sections were stained with XRCC5 and the results showed that TMZ could markedly induce the expression of XRCC5 in the xenograft tumors derived from U-87 MG-R cells (Fig. 5G). These results indicated the protective role of XRCC5 against TMZ treatment and may cause GBM cells to develop drug resistance.

\section{Discussion}

Collectively, functional screening using a shRNA library showed that XRCC5 was effective at increasing the 
cytotoxicity of GBM cells to TMZ. The association between XRCC5 mRNA expression level and clinical characteristics was subsequently analyzed using bioinformatics, and it was found that the expression level of XRCC5 in GMB specimens was higher compared with that in low grade glioma and normal brain tissue. In addition, high XRCC5 expression was also associated with lower overall survival. To verify the effect of XRCC5 on TMZ sensitivity, lentiviral shRNA was used to silence XRCC5, while pCMV was used to overexpress it and the effects on TMZ sensitivity were subsequently investigated. The results revealed that XRCC5 could increase cancer cell resistance to TMZ. In addition, TMZ-resistant cell lines were established and used in in vitro and in vivo experiments to further determine whether XRCC5 could be induced in the TMZ-resistant cells following TMZ treatment. In the U-87 MG and U-87 MG-R cell lines, the protein expression level of XRCC5 in the resistant cells was increased following TMZ treatment (at $125 \mu \mathrm{M}$ ), while it was decreased, from $250 \mu \mathrm{M}$, in the sensitive cells. Both the DBTRG-05MG and DBTRG-05MG-R cells had a significant increase in XRCC5 protein expression level following TMZ treatment. This could be the result of DBTRG-05MG itself being a relatively resistant cell line initially (37).

Eukaryotic cells depend on two major mechanisms for DNA: Repair homologous recombination (HR) or non-homologous end joining (NHEJ) (38). As DSB is important in TMZ-induced cell death, repairing DSB by HR and NHEJ could reduce the effect on the TMZ-triggered killing response. In GBM, DNA repair is highly variable, which has strong effects on TMZ resistance; therefore, DNA repair is an ideal choice for personalized treatment (39). Previous studies have shown that augmented HR repair is an important mechanism underlying acquired TMZ resistance in GBM (13). Once the components of HR, such as RAD51 (40), XRCC3 (11), BRCA1 (41), BRCC3 (42) and BRCA2 (43), were suppressed, glioma cells would be sensitive to TMZ. Similarly, numerous studies have also shown that some components of NHEJ, including XLF, 53BP1 (44), XRCC4 (45), DNA-PKcs (46) and DNA ligase IV (47), if they were inhibited, could enhance the therapeutic effect of TMZ.

XRCC5 is an important molecule in the NHEJ process (48). A previous study has shown that overexpression of XRCC5 in the NIH3T3 cell line derived from mouse embryonic fibroblasts could protect cells against $\gamma$-ray irradiation, leading to radioresistance (23). Similarly, in head and neck cancer, the protein expression of XRCC5 was significantly increased in radioresistant cells (24). Radiotherapy combined with cisplatin chemotherapy is the primary therapeutic strategy for cervical cancer and simultaneous inhibition of XRCC5 could increase sensitization in cervical cancer cells (27). In clinical lung adenocarcinoma specimens, chemoresistant tumors exhibited higher protein expression levels of XRCC5; therefore, XRCC5 could predict the responsiveness and prognosis in patients with lung cancer (25). Furthermore, XRCC5 overexpression was found to increase the resistance to chemotherapy drugs, while XRCC5 knockdown augmented drug sensitivity in lung cancer cells (26). In thyroid carcinoma, XRCC5 protein expression levels in carcinoma tissues were significantly higher compared with that in non-neoplastic adjacent tissue and XRCC5 knockdown decreased malignancy in thyroid cancer cells (29).
In chondrosarcoma, doxorubicin-resistant cells showed a dose-dependent increase in XRCC5 protein expression level following doxorubicin treatment, and silencing XRCC5 expression increased drug sensitivity in resistant cells (28).

Currently; however, there has been no study on the function of XRCC5 with respect to drug resistance in GBM, although one report showed that the DNA methylation level of XRCC5 in blood samples from patients with glioma was significantly higher compared with that in healthy individuals. In addition, XRCC5 methylation levels were significantly higher in patients treated with radiotherapy and chemotherapy compared with that in patients who were not treated (49). These studies indicated that the methylation level of XRCC5 in blood may be a potential indicator for evaluating the efficacy of radiotherapy and chemotherapy in patients with glioma. In a Han Chinese population, astrocytoma, another type of glioma, the XRCC5 genotype (SNP: rs9288516) was associated with increased risk of the disease and poor prognosis (50).

In conclusion, to the best of our knowledge, this is the first study to reveal the role of XRCC5 in TMZ resistance of GBM. An array-based shRNA library was used to inactivate KP gene activity and screen for genes, which leads to GBM cells becoming more sensitive to TMZ treatment. Of these genes, the knockdown of XRCC5 markedly sensitized GBM cells to TMZ-induced cell death. In addition, the clinical relevance of XRCC5 was analyzed using the cBioportal, Oncomine and R2 databases. The results showed that XRCC5 mRNA expression level was increased in GBM tissues and was associated with poor prognosis. In addition, in vitro and in vivo analyses revealed that XRCC5 could play a role in the protection against TMZ, suggesting that XRCC5 could be an effective target for the development of novel chemotherapy for treating drug resistant cancer cells.

\section{Acknowledgements}

Not applicable.

\section{Funding}

This study was supported by The Chang Gung Medical Research Council (grant nos.CMRPG6F0351,CMRPG6F0352 and CMRPG6F0353).

\section{Avaliability of data and materials}

The datasets used and/or analyzed in the current study are available from the corresponding author upon reasonable request. The datasets generated and/or analyzed during the current study are available in the cBioPortal (https://www.cbioportal. org/), Oncomine (https://www.oncomine.org/) R2 Genomics Analysis and Visualization Platform (https://hgserver1.amc. nl/cgi-bin/r2/main.cgi).

\section{Author's contributions}

INL, JTY designed and supervised the experiments, edited the manuscript and acquired funding. $\mathrm{CH}, \mathrm{HCH}$ analyzed the data. INL, YPW performed the experiments. JCC conceived, 
carried out experimental work, data analysis, manuscript preparation and editing. INL and JCC confirm the authenticity of all the raw data. All authors read and approved the final manuscript.

\section{Ethics approval and consent to participate}

Not applicable.

\section{Patient consent for publication}

Not applicable.

\section{Competing interests}

The authors declare that they have no competing interests.

\section{References}

1. Louis DN, Ohgaki H, Wiestler OD, Cavenee WK, Burger PC, Jouvet A, Scheithauer BW and Kleihues P: The 2007 WHO classification of tumours of the central nervous system. Acta Neuropathol 114: 97-109, 2007.

2. Ostrom QT, Cioffi G, Gittleman H, Patil N, Waite K, Kruchko C and Barnholtz-Sloan JS: CBTRUS Statistical Report: Primary brain and other central nervous system tumors diagnosed in the United States in 2012-2016. Neuro Oncol 21 (Suppl 5): v1-v100, 2019.

3. Yung WK, Albright RE, Olson J, Fredericks R, Fink K, Prados MD, Brada M, Spence A, Hohl RJ, Shapiro W, et al: A phase II study of temozolomide vs. procarbazine in patients with glioblastoma multiforme at first relapse. Br J Cancer 83: 588-593, 2000.

4. Hottinger AF, Ben Aissa A, Espeli V, Squiban D, Dunkel N, Vargas MI, Hundsberger T, Mach N, Schaller K, Weber DC, et al: Phase I study of sorafenib combined with radiation therapy and temozolomide as first-line treatment of high-grade glioma. $\mathrm{Br}$ J Cancer 110: 2655-2661, 2014

5. Fu D, Calvo JA and Samson LD: Balancing repair and tolerance of DNA damage caused by alkylating agents. Nat Rev Cancer 12 : 104-120, 2012.

6. Zhang J, Stevens MF and Bradshaw TD: Temozolomide: Mechanisms of action, repair and resistance. Curr Mol Pharmacol 5: 102-114, 2012.

7. Quiros S, Roos WP and Kaina B: Processing of O6-methylguanine into DNA double-strand breaks requires two rounds of replication whereas apoptosis is also induced in subsequent cell cycles. Cell Cycle 9: 168-178, 2010.

8. Bocangel DB, Finkelstein S, Schold SC, Bhakat KK, Mitra S and Kokkinakis DM: Multifaceted resistance of gliomas to temozolomide. Clin Cancer Res 8: 2725-2734, 2002.

9. Fan $\mathrm{CH}$, Liu WL, Cao H, Wen $\mathrm{C}$, Chen L and Jiang G: O6-methylguanine DNA methyltransferase as a promising target for the treatment of temozolomide-resistant gliomas. Cell Death Dis 4: e876, 2013.

10. Happold C, Roth P, Wick W, Schmidt N, Florea AM, Silginer M, Reifenberger G and Weller M: Distinct molecular mechanisms of acquired resistance to temozolomide in glioblastoma cells. J Neurochem 122: 444-455, 2012.

11. Roos WP, Frohnapfel L, Quiros S, Ringel F and Kaina B: XRCC3 contributes to temozolomide resistance of glioblastoma cells by promoting DNA double-strand break repair. Cancer Lett 424: 119-126, 2018.

12. Yang B, Fu X, Hao J, Sun J, Li Z, Li H and Xu H: PAXX Participates in Base Excision Repair via Interacting with Pol $\beta$ and Contributes to TMZ Resistance in Glioma Cells. J Mol Neurosci 66: 214-221, 2018.

13. Gil Del Alcazar CR, Todorova PK, Habib AA, Mukherjee B and Burma S: Augmented HR repair mediates acquired temozolomide resistance in glioblastoma. Mol Cancer Res 14: 928-940, 2016.

14. Stupp R, Mason WP, van den Bent MJ, Weller M, Fisher B, Taphoorn MJ, Belanger $\mathrm{K}$, Brandes AA, Marosi C, Bogdahn U, et al: Radiotherapy plus concomitant and adjuvant temozolomide for glioblastoma. N Engl J Med 352: 987-996, 2005 .
15. Hata N, Mizoguchi M, Kuga D, Hatae R, Akagi Y, Sangatsuda Y, Amemiya T, Michiwaki Y, Fujioka Y, Takigawa K, et al: First-line bevacizumab contributes to survival improvement in glioblastoma patients complementary to temozolomide. J Neurooncol 146: 451-458, 2020.

16. Caplen NJ, Parrish S, Imani F, Fire A and Morgan RA: Specific inhibition of gene expression by small double-stranded RNAs in invertebrate and vertebrate systems. Proc Natl Acad Sci USA 98: 9742-9747, 2001.

17. Agrawal N, Dasaradhi PV, Mohmmed A, Malhotra P, Bhatnagar RK and Mukherjee SK: RNA interference: Biology, mechanism, and applications. Microbiol Mol Biol Rev 67: 657-685, 2003.

18. Salm F, Cwiek P, Ghosal A, Lucia Buccarello A, Largey F, Wotzkow C, Höland K, Styp-Rekowska B, Djonov V, Zlobec I, et al: RNA interference screening identifies a novel role for autocrine fibroblast growth factor signaling in neuroblastoma chemoresistance. Oncogene 32: 3944-3953, 2013.

19. Ding Y, Huang D, Zhang Z, Smith J, Petillo D, Looyenga BD, Feenstra K, Mackeigan JP, Furge KA and The BT: Combined gene expression profiling and RNAi screening in clear cell renal cell carcinoma identify PLK1 and other therapeutic kinase targets. Cancer Res 71: 5225-5234, 2011.

20. Pannunzio NR, Watanabe G and Lieber MR: Nonhomologous DNA end-joining for repair of DNA double-strand breaks. J Biol Chem 293: 10512-10523, 2018.

21. Meek K, Dang V and Lees-Miller SP: DNA-PK: The means to justify the ends? Adv Immunol 99: 33-58, 2008.

22. Lieber MR: The mechanism of double-strand DNA break repair by the nonhomologous DNA end-joining pathway. Annu Rev Biochem 79: 181-211, 2010.

23. Chang IY, Youn CK, Kim HB, Kim MH, Cho HJ, Yoon Y, Lee YS, Chung MH and You HJ: Oncogenic H-Ras up-regulates expression of Ku80 to protect cells from gamma-ray irradiation in NIH3T3 cells. Cancer Res 65: 6811-6819, 2005.

24. Chang HW, Kim SY, Yi SL, Son SH, Song DY, Moon SY, Kim JH, Choi EK, Ahn SD, Shin SS, et al: Expression of Ku80 correlates with sensitivities to radiation in cancer cell lines of the head and neck. Oral Oncol 42: 979-986, 2006.

25. Ma Q, Li P, Xu M, Yin J, Su Z, Li W and Zhang J: Ku80 is highly expressed in lung adenocarcinoma and promotes cisplatin resistance. J Exp Clin Cancer Res 31: 99, 2012.

26. Shang B, Jia Y, Chen G and Wang Z: Ku80 correlates with neoadjuvant chemotherapy resistance in human lung adenocarcinoma, but reduces cisplatin/pemetrexed-induced apoptosis in A549 cells. Respir Res 18: 56, 2017.

27. Zhuang L, Liu F, Peng P, Xiong H, Qiu H, Fu X, Xiao Z and Huang X: Effect of Ku80 on the radiosensitization of cisplatin in the cervical carcinoma cell line HeLa. Oncol Lett 15: 147-154, 2018.

28. Hsieh MJ, Huang C, Lin CC, Tang CH, Lin CY, Lee IN, Huang $\mathrm{HC}$ and Chen JC: Basic fibroblast growth factor promotes doxorubicin resistance in chondrosarcoma cells by affecting XRCC5 expression. Mol Carcinog 59: 293-303, 2020.

29. Fan Y, Li J, Wei W, Fang H, Duan Y, Li N, Zhang Y, Yu J and Wang J: Ku80 gene knockdown by the CRISPR/Cas9 technique affects the biological functions of human thyroid carcinoma cells. Oncol Rep 42: 2486-2498, 2019.

30. Torcivia-Rodriguez J, Dingerdissen H, Chang TC and Mazumder R: A primer for access to repositories of cancer-related genomic big data. Methods Mol Biol 1878: 1-37, 2019.

31. Saha SK, Islam SMR, Kwak KS, Rahman MS and Cho SG: PROM1 and PROM2 expression differentially modulates clinical prognosis of cancer: A multiomics analysis. Cancer Gene Ther 27: 147-167, 2020.

32. Tang C, Chen E, Peng K, Wang H, Cheng X, Wang Y, Yu S, Yu Y, Cui Y and Liu T: Mining the role of angiopoietin-like protein family in gastric cancer and seeking potential therapeutic targets by integrative bioinformatics analysis. Cancer Med 9: 4850-4863, 2020.

33. Osuka S and Van Meir EG: Overcoming therapeutic resistance in glioblastoma: The way forward. J Clin Invest 127: 415-426, 2017.

34. Shergalis A, Bankhead A III, Luesakul U, Muangsin N and Neamati N: Current challenges and opportunities in treating glioblastoma. Pharmacol Rev 70: 412-445, 2018.

35. Gusev Y, Bhuvaneshwar K, Song L, Zenklusen JC, Fine H and Madhavan S: The REMBRANDT study, a large collection of genomic data from brain cancer patients. Sci Data 5: 180158, 2018.

36. Schmittgen TD and Livak KJ: Analyzing real-time PCR data by the comparative C(T) method. Nat Protoc 3: 1101-1108, 2008. 
37. Chen JC, Lee IN, Huang C, Wu YP, Chung CY, Lee MH, Lin MH and Yang JT: Valproic acid-induced amphiregulin secretion confers resistance to temozolomide treatment in human glioma cells. BMC Cancer 19: 756, 2019.

38. Chapman JR, Taylor MR and Boulton SJ: Playing the end game: DNA double-strand break repair pathway choice. Mol Cell 47: 497-510, 2012

39. Kaina B and Christmann M: DNA repair in personalized brain cancer therapy with temozolomide and nitrosoureas. DNA Repair (Amst) 78: 128-141, 2019.

40. Quiros S, Roos WP and Kaina B: Rad51 and BRCA2-New molecular targets for sensitizing glioma cells to alkylating anticancer drugs. PLoS One 6: e27183, 2011.

41. Ding J, Wu S, Zhang C, Garyali A, Martinez-Ledesma E, Gao F, Pokkulandra A, Li X, Bristow C, Carugo A, et al: BRCA1 identified as a modulator of temozolomide resistance in P53 wild-type GBM using a high-throughput shRNA-based synthetic lethality screening. Am J Cancer Res 9: 2428-2441, 2019.

42. Chai KM, Wang CY, Liaw HJ, Fang KM, Yang CS and Tzeng SF: Downregulation of BRCA1-BRCA2-containing complex subunit 3 sensitizes glioma cells to temozolomide. Oncotarget 5 : 10901-10915, 2014.

43. Kondo N, Takahashi A, Mori E, Noda T, Zdzienicka MZ, Thompson LH, Helleday T, Suzuki M, Kinashi Y, Masunaga S, et al: FANCD1/BRCA2 plays predominant role in the repair of DNA damage induced by ACNU or TMZ. PLoS One 6: e19659, 2011.

44. Zhang T, Chai J and Chi L: Induction Of XLF And 53BP1 expression is associated with temozolomide resistance in glioblastoma cells. Onco Targets Ther 12: 10139-10151, 2019.

45. Zeng A, Wei Z, Yan W, Yin J, Huang X, Zhou X, Li R, Shen F, Wu W, Wang X and You Y: Exosomal transfer of miR-151a enhances chemosensitivity to temozolomide in drug-resistant glioblastoma. Cancer Lett 436: 10-21, 2018.
46. Roos WP, Batista LF, Naumann SC, Wick W, Weller M, Menck CF and Kaina B: Apoptosis in malignant glioma cells triggered by the temozolomide-induced DNA lesion O6-methylguanine. Oncogene 26: 186-197, 2007.

47. Kondo N, Takahashi A, Mori E, Ohnishi K, McKinnon PJ, Sakaki T, Nakase H and Ohnishi T: DNA ligase IV as a new molecular target for temozolomide. Biochem Biophys Res Commun 387: 656-660, 2009.

48. Meek K, Gupta S, Ramsden DA and Lees-Miller SP: The DNA-dependent protein kinase: The director at the end. Immunol Rev 200: 132-141, 2004.

49. Zhou C, Tang H, Yu J, Zhuang D and Zhang H: Blood-based DNA methylation of DNA repair genes in the non-homologous end-joining (NEHJ) pathway in patient with glioma. Int J Clin Exp Pathol 8: 9463-9467, 2015.

50. He X, Zhu X, Li L, Zhang J, Wu R, Zhang Y, Kang L, Yuan D and Jin T: The relationship between polymorphisms of XRCC5 genes with astrocytoma prognosis in the Han Chinese population. Oncotarget 7: 85283-85290, 2016.

This work is licensed under a Creative Commons Attribution-NonCommercial-NoDerivatives 4.0 International (CC BY-NC-ND 4.0) License. 